\title{
Dibujar para subvertir: Cuerpo, género y poder en las crónicas y los diarios gráficos de Marcela Trujillo (o Maliki 4 Ojos)
}

A través de su personaje autobiográfico Maliki 4 Ojos, Marcela Trujillo crea un puente entre la crónica, el diario y el cómic. Desde allí, examina los estereotipos que la mirada masculina hegemónica ha impuesto sobre el cuerpo y la sexualidad de la mujer. La consecución del placer sexual es presentada como desvinculada de la maternidad e incluye el autoerotismo. La maternidad se presenta en un juego dialéctico con la monstruosidad, una combinación de idea y dibujo que es un contradiscurso de la madre ideal o perfecta según la perspectiva sociocultural dominante.

Palabras clave: Marcela Trujillo, cómic, autobiografía, representación del cuerpo y sexualidad femeninos, representación de la maternidad.

Through her autobiographical character, Maliki 4 Ojos, Marcela Trujillo bridges genres such as the chronicle, the intimate diary, and comics. She examines the stereotypes that the hegemonic male gaze has imposed on the body and women's sexuality. The attainment of sexual pleasure is presented as detached from motherhood and includes autoeroticism. Motherhood is portrayed in a dialectical exchange with monstrosity, using a combination of ideas and drawings that functions as counter-discourse to the representation of the ideal or perfect mother according to the dominant socio-cultural perspective.

Keywords: Marcela Trujillo, comics, autobiography, representation of the female body and sexuality, representation of motherhood.

Marcela Trujillo (Santiago, Chile, 1969) debutó en el mundo del libro de historietas con Las crónicas de Maliki 4 Ojos (2010), aun cuando sus incursiones en el mundo del cómic se habían iniciado años antes. A su primer libro le siguieron El diario íntimo de Maliki 4 Ojos (2OII), El diario 
iluminado de Maliki 4 Ojos (2013) y Quiero ser flaca y feliz (2015), escrito con la psicóloga Karolina Lama. En 2OI7, publicó su primera novela gráfica, Ídolo, una historia casi real. En junio de 2018 - junto a Isabel Molina, Sol Díaz, Pati Aguilera y Paloma Rodríguez - fundó Brígida, una revista de cómic hecha por mujeres. Marcela Trujillo estudió Licenciatura en Artes Plásticas en la Universidad de Chile, especializándose en pintura. Posteriormente, residió siete años en la ciudad de Nueva York, donde obtuvo diplomas en Bellas Artes y en Animación y Guion Gráfico. Ha expuesto su obra pictórica en diversas salas, tanto en Chile como en los Estados Unidos, Canadá y Finlandia. Fue durante los dos últimos años de su estadía en Nueva York que Trujillo se abocó a desarrollar la figura de Maliki 4 Ojos, un personaje decididamente autobiográfico. Estos primeros cómics fueron publicados en el semanario chileno The Clinic. Durante los años 2002 y 2003, Trujillo publicó las Crónicas íntimas de una chilena en la Gran Manzana. Luego de mudarse a Alemania, publicó Malikimamá, aventuras de madre y esposa, también en The Clinic (2006). De regreso en Chile, Malikiadulta se publicó en el mismo semanario (2008), cuyos originales fueron exhibidos en la Galería Gabriela Mistral, en Santiago. No será sino hasta el año 20 Io que Trujillo publique en un solo volumen los cómics aparecidos en The Clinic entre los años 2002 y 2008, bajo el título de Las crónicas de Maliki 4 Ojos.

Aunque Marcela Trujillo no pertenece a la actual generación de escritoras chilenas calificadas de "osadas y crudas" por Matías Rivas, sí puede considerársela como parte del grupo que fue su antecedente directo. En efecto, en las décadas de los ochenta y noventa salen a la luz autoras que se dedicaron a escribir acerca de mujeres y cuyas obras manifestaban una fuerte influencia de "la literatura norteamericana, el cine oriental, el animé, los estudios universitarios y los talleres literarios ... son autoras formadas en la academia y en el pop, que asumen la estrategia sin complejos ni miedos a la hora de inscribirse" (Rivas). Al repasar los rasgos que singularizan los textos de las "osadas y crudas" - entre las que Rivas menciona a Paulina Flores, Camila Gutiérrez e Isabel Margarita Bustos, todas menores de cuarenta años - notamos que esas características ya se hallaban en las obras de las autoras que, como Marcela Trujillo, comienzan a publicar o a realizar sus estudios académicos en la década de los ochenta. Como veremos, la obra de Trujillo se enmarca dentro de "una literatura de mujeres dispuestas a correr riesgos, revisar la tradición y a entregar obras que asumen la incomodidad contemporánea con una disposición desafiante" (Rivas).

En este ensayo quisiera proponer que, a través del personaje autobiográfico Maliki 4 Ojos, Marcela Trujillo no solo crea un puente entre el diario íntimo y el cómic, sino que - más importante aún - socava ciertas 
ideas e imágenes de la mujer que gozan de una aceptación social casi inmutable. Así, Trujillo explora las constricciones que un canon de belleza forjado por la mirada masculina ha impuesto sobre el cuerpo de la mujer. La sexualidad femenina, por su parte, es presentada sin tapujos. Trujillo descubre ante el lector no solo el cuerpo femenino con sus deseos satisfechos e insatisfechos, con sus más recónditos espacios, con sus fluidos y sus reacciones ante la estimulación, sino que también grafica su propia mirada sobre el cuerpo del hombre, invirtiendo el punto de vista masculino hegemónico. La mujer - visualizada como un ente tan erótico como suele representarse al hombre - no solo verbaliza sus deseos y fantasías, sino que también es activa en la búsqueda de sus compañeros sexuales. La mujer dibujada por Trujillo se lanza a la conquista de un placer despegado de la maternidad, placer que ciertamente incluye el autoerotismo. La maternidad es mostrada en un constante juego dialéctico con lo que Trujillo denomina "monstruosidad", idea-dibujo que se alza como un contradiscurso de la figura de la madre ideal o "perfecta" según la perspectiva social y cultural dominante (El diario iluminado II). Trujillo subvierte nociones prevalentes en la sociedad chilena actual, donde todavía la figura materna se asocia fuertemente con valores que empujan a que la mujer se niegue a la autorrealización como profesional, como ente político y como ente erótico.

Dado lo anterior, no cabe duda de que la obra de Marcela Trujillo enfrenta al lector a una serie de desafíos. Sus libros son un espacio en el que concurren y se cruzan diferentes géneros literarios y expresiones artísticas, tales como el diario íntimo, el autorretrato, la autobiografía y el cómic. En cada uno de sus libros - y a través del uso de la técnica del lápiz grafito, la plumilla y el pincel con tinta china siempre negra - la autora nos ofrece su estética "muchista", expresión inventada por ella para referirse al estilo sobrecargado y excesivo de numerosos templos católicos y que, sin embargo, la atrae poderosamente (Diario íntimo 72). En efecto, las páginas de sus libros tienen, como seña de identidad, una tendencia al horror vacui, dado que la autora llena todo el espacio con figuras y letras traspasadas de movimiento: se trata de una escritura que crece y se achica, que adquiere formas líquidas, rugosas, espinudas, eléctricas, peludas, mullidas, entre muchas otras, todo ello para revelar estados anímicos causados por experiencias personales con las que la mayoría de las mujeres se puede identificar. Sus cómics se valen persistentemente del humor, no faltando lo caricaturesco, componente que no tiene necesariamente un propósito satírico o de ridiculización. Su personaje Maliki 4 Ojos - que se caracteriza por tener dos ampolletas o bombillas eléctricas en la cabeza - pasa por las diferentes etapas de desarrollo de su creadora (infancia, juventud y 
embarazo, entre otras). Maliki 4 Ojos es, de este modo, el alter ego de Trujillo. A través del personaje, la autora ficcionaliza su vida y sus reflexiones sobre ese acontecer vital.

Por otra parte, la opción por el diario íntimo nos pone frente a obras que, supuestamente, no están pensadas para ser leídas sino por quien las escribió. Como explica Manuel Hierro, el diario íntimo "en su origen no está destinado a salir de los confines de su secreto personal" (IO3). Con todo, Hierro y otros estudiosos de este género (como Álvaro Luque Amo y Amelia Cana Calderón) no niegan la naturaleza íntima del diario porque éste pase a ser de dominio público. Según Andrés Trapiello, "nadie que lleve un diario ha renunciado a que pueda ser leído alguna vez por otro" (28). Sin embargo, no es lo mismo que un diario salga a la luz pública una vez que su autor ha muerto a que un diario sea tildado de íntimo por su autora y que esta misma lo conciba, escriba y dibuje con vistas a ser publicado. Esta decisión de la autora expande las fronteras de este género literario o, al menos, las problematiza. El que los diarios de Maliki hayan sido ideados para ser publicados instala inmediatamente la distinción entre autora y personaje. En efecto, Marcela Trujillo produce una imagen de sí misma - Maliki 4 Ojos - que le permite re-posicionarse en su propia biografía y así llegar a ser autora de su identidad como mujer. A través de Maliki, Trujillo visita los diversos momentos de su pasado y rechaza los estereotipos que han pretendido fijar su identidad desde afuera, optando, en cambio, por autodefinirse a partir de sí. Esta característica hace que la obra de Trujillo sea profundamente metaficcional, pues, como Patricia Waugh explica, la metaficción plantea preguntas sobre la relación entre la ficción y la realidad en tanto que explora la posible ficcionalidad del mundo extra-textual (2): así como Trujillo ficcionaliza su propia vida por medio de su personaje, así también la realidad que existe fuera de sus libros puede ser igualmente reinventada. La construcción de subjetividades por parte de personajes ficticios sirve de modelo para comprender la construcción de la subjetividad de las personas reales que existen fuera de la ficción, asevera Waugh (3). Y si nuestro conocimiento del mundo está mediado por el lenguaje, entonces las obras de ficción (mundos construidos completamente de lenguaje) pueden servir como pauta para aprender sobre la construcción de eso que llamamos realidad (Waugh 3 ).

Para Hans Rudolf Picard, el diario, como género literario,

es estructuración lingüística, es un modo como una conciencia organiza sus reacciones frente a la realidad. Como producto lingüístico de una autoconciencia, el diario no es en absoluto un documento sobre la manera como un individuo se limita 
a constatar de un modo neutral cómo se encuentra en el mundo; todo lo contrario: en su calidad de confesión centrada sobre sí mismo, el diario es la imagen filtrada a través de un temperamento particular, el proyecto de una idea, más inconsciente que consciente, que el yo tiene de sí mismo. (II0)

Y estas características están muy presentes en los diarios creados por Trujillo. El lector entra en el mundo de Maliki y accede a esa "imagen filtrada" que Trujillo tiene de sí. Incluso la introducción de El diario íntimo de Maliki 4 Ojos - que, como paratexto, busca llamar la atención sobre el diario que sigue a continuación y comenta sobre él - es ya la primera entrada del diario y viene firmada por Maliki 4 Ojos. Esto indica que, desde el comienzo del texto, Trujillo le da la palabra a Maliki, esa entidad lingüística-visual a través de la cual interpreta su historia personal y se atreve a salir del ámbito privado a la esfera pública. Aplicando la definición de Picard, los diarios de Maliki no son un documento neutral, sino una imagen creada por medio de un personaje que tiene deseos, sentimientos y emociones, que ha meditado sobre los roles de género, la sexualidad, el matrimonio y la maternidad, entre otras cosas, y que actúa como la voz pública de Trujillo.

A través de una narración autobiográfica, Maliki nos dice que de niña tenía un diario de vida y que la inquietaba que otras personas lo pudieran leer. Reflexiona sobre su actual decisión de hacer un diario para que sea publicado: "Cuando pienso, el hecho de querer ocultar lo que escribía y de mantenerlo en privado indicaba que tenía secretos o una intimidad que proteger. Eso me provoca una ternura porque la intención de este diario es precisamente lo contrario" (Diario íntimo 20-2I). Maliki señala que empezó a escribir sobre sus propios recuerdos bajo sugerencia de un psicólogo, lo cual la ayudó a comprender su historia personal y a revisar su pasado para descubrir sus secuelas en su presente vital. Esta experiencia terapéutica estaría en la base de sus crónicas y el deseo de averiguar hasta qué punto coinciden o se separan la imagen que ella tiene de sí misma con la que proyecta hacia los demás. Esta búsqueda es lo que queda plasmado en sus diarios, y el personaje es tan franco que induce a pensar que estamos ante un diario escrito para permanecer en el reino de lo privado. Trujillo, a través de Maliki, se hace cargo de este asunto:

... [M] uchas personas me han preguntado porqué expongo mis intimidades sin pudor, si no me da "vergüenza" hacerlo, qué me pasa cuando decido compartir cosas que nadie habla porque se supone que hay que tener cierta.... privacidad, guardar ciertas proporciones, $\mathrm{y}$ todo para tener integridad y decencia. 
Y yo creo que las personas somos muy temerosas de crear ciertas impresiones que nos hagan ver débiles, mediocres, pencas, comunes y corrientes... ¿humanos? Sí, humanos que se equivocan, que no triunfan, que no les va tan bien, que son feos, que son quemados, que son infelices... (Diario íntimo 24-25)

Es claro que la autora busca tener un impacto en el receptor. Y, como sostiene Picard, las estrategias comunicativas con vistas a ejercer un efecto sobre el lector, así como la selección de los contenidos, le restan libertad al diario que se concibe desde un inicio para ser publicado y donde la inmediatez de lo narrado no es sino una inmediatez imitada (II8). El diario, entonces, pasa a ser literatura y el autor se transforma en un personaje literario. Así, lo que en un auténtico diario no es algo que vaya a ser ofrecido a la mirada de otros, en el diario con vistas a ser publicado se convierte en "intimidad presentada", ya que, a través de recursos artísticos, lo invisible es transformado en visible (Picard 120 ).

Lo dicho cobra mayor relevancia al tratarse de un diario escrito por una mujer, ya que revela, desde la esfera íntima, una identidad que ha sido forzada a la invisibilidad. Por medio del diario, así como del escrito autobiográfico, las mujeres han intentado irrumpir en una esfera pública dominada por el lenguaje masculino y su forma de interpretar el mundo, un modo de decir que, bajo su pretendida universalidad, asegura incorporar y expresar también a la mujer. Sin embargo, en vez de ser incluida, la especificidad de la mujer resulta anulada, pues lo que prevalece es el punto de vista masculino, el cual, como señala Molly Hite, aparece como coherente porque ha suprimido otras maneras de mirar y contar las cosas, versiones alternativas que podrían dar a la misma secuencia de eventos unos énfasis y valores completamente diferentes (4). De esta forma, al hacer emerger una intimidad a través de sus diarios, Marcela Trujillo parece sostener que existe una subjetividad diferente que exige ser dicha y representada, una subjetividad que protesta ante el silencio impuesto desde discursos que expresan modelos masculinos de subjetividad y que se presentan como universales. En este sentido, el diario, al ser un género tan ligado a la subjetividad de quien escribe, le permite a Maliki - y a Trujillo detrás de ella - desafiar las construcciones sociales que, desde la mirada masculina hegemónica, han configurado su identidad. Por lo mismo, es un proceso de escritura que implica un desgarro interno: al denunciar y separarse de la construcción social que la ha formado, se produce también una disolución de la identidad que hasta entonces había asumido. Se trata de un camino zigzagueante, alejado de esa coherencia con que, como señala Hites, se presenta el discurso masculino. El diario escrito por mujeres descorre un 
velo para mostrar que sí hay otra forma de producir subjetividad. En el fondo, saca a la luz la diferencia que la pretendida universalidad del discurso masculino niega al expulsarla de los modos socialmente preponderantes de dar significado al mundo. Los diarios de Maliki, en este contexto, hacen patente la existencia de un sujeto femenino que tiene una percepción de sí y unos deseos que no coinciden con los estereotipos que le han sido inculcados y que ella misma ha adoptado. A través de la elaboración de los diarios, el personaje va estructurando su identidad. A su vez, esa identidad diferenciada va moldeando el texto, generándose un juego dinámico entre escritura y creación de la propia subjetividad. El diario posibilita la invención de una voz personal, inherente, constitutiva. Maliki deja así de ser dicha por el discurso hegemónico masculino y pasa a hacerse socialmente significativa a través de un discurso producido desde sí misma y que articula su identidad. Desafía la perspectiva dominante que, aunque ejerce un control sobre la mujer, no llega a comprender su alteridad.

Trujillo misma señala que sus diarios unen el cómic con elementos autobiográficos, vínculo que, como explica Elisabeth El Refaie, permite que la autobiografía se enriquezca con las tradiciones socioculturales y las características formales del cómic (3). Según El Refaie, el cómic tiene una larga historia de estar en los márgenes de la sociedad "culta"; por ello, los artistas cuentan sus historias autobiográficas incorporando temas que rompen con los tabúes y empleando el humor subversivo y la ironía (4). Algo fundamental en el cómic autobiográfico, de acuerdo con El Refaie - y que sin lugar a duda vemos en los libros de Marcela Trujillo - es que el género descansa en imágenes, lo cual lleva al artista a producir múltiples dibujos de sí mismo y, por lo tanto, a concentrarse en los aspectos corporales de la propia identidad tanto como en los modelos socioculturales que sustentan una imagen del cuerpo (4). Es precisamente la representación de una identidad incorporada lo que le permite a Trujillo abordar temas relacionados con la mirada masculina y las expectativas culturales que configuran el cuerpo de la mujer. Y esa identidad incorporada es la suya propia - a través de su alter ego - puesta en palabras y en dibujos.

Es fundamental entender cuál es la imagen de sí que Trujillo presenta a través del personaje Maliki 4 Ojos. No se trata solamente de la narración de unas anécdotas ni de los efectos emocionales y psicológicos que estas hayan tenido en el personaje. Precisamente porque los diarios de Maliki son cómics, lo que tenemos es un autorretrato. El lector tiene acceso a mucho más que una semblanza hecha de palabras, pues, literalmente, ve a Maliki. De esta manera, observamos los dibujos que la autora hace de sí misma. Trujillo retrata a su personaje - y se autorretrata - en diversas etapas de su 
vida. La subjetividad inherente a todo autorretrato - y que lleva al autor a elegir y acentuar algunas características que él considera determinantes de su identidad - se encuentra presente en las representaciones gráficas de Maliki. Con todo, es una imagen que integra no solo contenidos de corte autobiográfico, sino también elementos que hacen referencia al entorno social y cultural de la autora, como las ideas preconcebidas sobre la mujer que son prevalentes en la sociedad chilena.

Los detallados dibujos de Trujillo se aproximan y se separan de la tradición del retrato retórico. Según André Michalski,

El retrato retórico, es decir, la descripción pormenorizada del cuerpo humano, considerando sus partes sucesivamente de arriba para abajo, es un tópico literario, llamado anatomía o effictio, que se remonta a los albores mismos de las letras occidentales y tiene su auge en los dechados de belleza femenina que abundan en la literatura europea de la Edad Media y del Renacimiento. (39)

Trujillo, en efecto, dibuja a Maliki, pasando revista a cada una de las partes de su cuerpo. Se aparta, sin embargo, hasta cierto punto del retrato retórico porque, como Michalski aclara, cuando se trataba de mujeres hermosas, "fuera del rostro y de la cabeza, solo se permite describir las manos y, ya rayando en la licencia, los pies, mientras que, si ... la effictio es de una bruja repugnante, entonces el retrato es de cuerpo entero y desnudo" (42). Como se ha apuntado, Maliki aparece retratada en diversas fases de su vida y exhibiendo diferentes estados físicos. Si en los cómics sobre su estadía en Nueva York luce una figura esbelta con la que se siente cómoda y satisfecha, en sus diarios la encontramos luchando contra la obesidad. En ambos casos Trujillo dibuja a su personaje completamente desnudo. No se conforma con retratar el rostro, las manos y los pies cuando lo que desea mostrar es la felicidad que todo su cuerpo le prodiga, invitando al lector a curiosear incluso en sus rincones más íntimos. Por otra parte, tampoco procede con crueldad cuando presenta el cuerpo del personaje deteriorado a causa del sobrepeso. En el autorretrato de Trujillo - plasmado en la figura de Maliki - la "effictio" tal y como la encontramos en la literatura medieval y renacentista es desplazada por una representación un tanto caricaturesca que, con humor, busca aproximarse a la permanente lucha de la autora contra los kilos. Así, el cuerpo de Maliki se transforma en el campo donde se libra la batalla entre los clichés sobre la belleza femenina y una imagen de sí misma que brota de convicciones profundas acerca del cuerpo de la mujer $y$, en definitiva, de su propio cuerpo. 
Casi en la mitad de El diario íntimo de Maliki 4 Ojos, la autora nos mete de lleno en el tema del cuerpo de la mujer a través de la representación del cuerpo de su alter ego. El apartado se inicia con la frase "Querido Diario: Estoy a DIETA ..." (гоo), pasando a detallar en qué consiste su régimen alimenticio. No obstante, son los dibujos los más elocuentes, ya que plantean que la motivación para someterse a una dieta es poder atraer a algún hombre. Maliki aparece caricaturizada en las etapas de antes y durante la dieta, la fase de tomar pastillas para adelgazar hasta el momento en que se rinde y abandona su propósito. En estas ilustraciones, presenciamos la excitación de Maliki mientras fantasea acerca de la posibilidad de seducir a algún hombre y poder tener una vida sexual activa; la observamos comiéndose las uñas y transpirando ansiosamente mientras, con los ojos llenos de angustia, se imagina devorando todo aquello que le está prohibido; y la vemos comparándose con mujeres delgadas a la vez que sueña que ha logrado su peso ideal luego de haber tomado píldoras para adelgazar y se figura posando como una modelo en una pasarela. Finalmente, claudica, y quizás esto pase porque la razón para perder peso no radica en una convicción que nazca desde sí misma. El cuerpo prototípico que Maliki quisiera exhibir no ha sido ideado por ella ni por las esbeltas mujeres con las que se compara. Al contrario, mientras más intenta configurarse de acuerdo con esos cánones, más parece desperfilarse su identidad. Maliki expresa su deseo de que hubiera un Photoshop en la vida real mientras juzga su apariencia física en un dibujo que titula "Maliki cero" (figura I), aludiendo a que ella se caracteriza por tener "cero cintura", "cero cuello", "cero entrepierna", entre otras partes de su cuerpo, para concluir que tiene "cero ganas" de subirse a la pesa. Todo esto sería la causa de que tenga "cero pololo" o "cero peor es ná", nombres que se usan en Chile para llamar al novio informal.

Sin duda, la mirada que Maliki tiende sobre su propio cuerpo se halla, en esta etapa, colonizada por la mirada masculina hegemónica. Maliki tiene una imagen menoscabada de sí dado que no llena las expectativas que la mirada masculina ha creado sobre el cuerpo de la mujer. Ante esto, desaparecen los atributos de la personalidad, pues la mujer es cuerpo y éste debe adaptarse al modelo culturalmente vigente. Como Laura Mulvey explica:

Woman then stands in patriarchal culture as signifier for the male other, bound by a symbolic order in which man can live out his phantasies and obsessions through linguistic command by imposing them on the silent image of woman still tied to her place as bearer of meaning, not maker of meaning. (343) 
La ilustración "Maliki cero" expone el reverso del paradigma de belleza femenina producido por la mirada masculina para su propio placer. Hace presente el código patriarcal imperante justamente porque el personaje valida ese código desde la carencia. Como Mulvey arguye:

In a world ordered by sexual imbalance, pleasure in looking has been split between active/male and passive/female. The determining male gaze projects its phantasy on to the female figure which is styled accordingly. In their traditional exhibitionist role women are simultaneously looked at and displayed, with their appearance coded for strong visual and erotic impact so that they can be said to connote to-be-looked-atness. Woman displayed as sexual object is the leitmotif of erotic spectacle: from pinups to striptease, from Ziegfeld to Busby Berkeley, she holds the look, plays to and signifies male desire. (346)

En efecto, al decir que posee "cero cintura" o "cero cuello", Maliki se está recriminando por no encarnar el ideal diseñado por la mirada masculina y por no poder ser considerada objeto de deseo de esa mirada. La palabra "cero", lejos de ser una negación contestaria o un contradiscurso del código patriarcal que la constriñe, es un reproche dirigido hacia sí misma que prueba cuán desesperadamente desea insertarse en ese régimen de la mirada. De este modo, Maliki confirma una imagen cosificada de la mujer que es la que puede brindar placer a la mirada del hombre.

Con todo, esta representación que Maliki esboza de sí misma corresponde a un primer estadio de la búsqueda de una imagen que la satisfaga. En El diario iluminado de Maliki 4 Ojos, se presenta un posible punto de quiebre en la evaluación que el personaje hace de sí al recibir una llamada telefónica de la novia de su ex-esposo a fin de reclamarle por haber hecho públicos ciertos detalles de su vida privada. Lo interesante de este episodio es que lo único que parece trastornar a Maliki es el modo como la mujer la adjetiva, lo cual queda extremadamente claro en la ilustración que incluye no solo el párrafo completo que la indignada mujer le lanza a gritos, sino, de manera destacada, las dos expresiones que, como Maliki asevera, logran liquidarla: “¡Guatona asquerosa! ¡Gorda horrible!” (65).

Este episodio y otras dificultades por las que el personaje atraviesa, llevan a Maliki a enfrentar un cambio profundo en su estilo de vida. Con el apoyo de su familia y amistades cercanas, se embarca en un proyecto de largo aliento en el cual conoce a la psicóloga Karolina Lama, con quien publica Quiero ser flaca y feliz. La nueva mirada de Maliki hacia su cuerpo nace de un aprendizaje sobre la importancia de su bienestar intrínseco tanto 
físico como psicológico. Este cambio se basa en la toma de conciencia de las construcciones sociales que atrapan a los individuos hasta el punto de, como Maliki declara, definirlos como persona. Poco a poco, Maliki va liberándose de sus adicciones - las que van desde el azúcar hasta las redes sociales - al irse compenetrando más consigo misma y entendiendo que esas dependencias, en el fondo, tratan de llenar un profundo vacío emocional. El personaje logra tener el cuerpo que desea, pero no ya para el deleite de una mirada masculina que la cosifica, sino para su propia satisfacción, llegando a ser agente activo de su propia transformación y artífice de su nueva imagen. Maliki aprende que ella tiene importancia por y para sí misma.

La representación del cuerpo de la mujer halla uno de sus puntos cruciales en el modo como Trujillo aborda el erotismo femenino. En los cómics publicados en The Clinic entre los años 2002 y 2008 , la autora explora sin censura la sexualidad femenina. En el capítulo titulado "Crónicas íntimas de una chilena en la Gran Manzana", Trujillo incluye historias en las que aborda la importancia del tamaño del pene, celebra la práctica masturbatoria, expresa su miedo cerval al embarazo y a la maternidad, busca el origen de sus tendencias exhibicionistas y narra su encuentro en Alemania con quien llegará a ser su esposo y el padre de sus dos hijas. Estos temas, así como la manera en la que Trujillo se aproxima a ellos, no dejaron de causar revuelo en el ambiente chileno.

En efecto, en una larga conversación que sostuve con la autora en febrero del año 20I7, esta recordó el impacto que su crónica "Enamorada de mi clítoris" (figura 2) causó en los editores de The Clinic. Si se toma en cuenta que este semanario es una revista que se caracteriza por un tono irreverente para tratar temas del acontecer social y político chileno, y que se precia, además, de presentar una perspectiva progresista en temas relativos a la moral sexual, la reacción del comité editorial fue inesperada. El cómic sobre el autoerotismo femenino parece haber empujado los límites más allá de lo que el liberalismo de The Clinic estaba dispuesto a tolerar y, aunque la crónica fue publicada, se le criticó a la autora que se haya excedido y se le sugirió que tuviera esto en consideración para las siguientes colaboraciones con la revista. Si se observa que muchas de las historietas creadas por Marcela Trujillo durante su estadía en la ciudad de Nueva York son de un pronunciado tinte erótico, en donde tanto el cuerpo de Maliki como el de sus diversos compañeros sexuales son presentados desnudos y llevando a cabo todo tipo de prácticas, incluyendo el sexo oral, ¿por qué los editores de The Clinic presentaron reparos ante la representación gráfica del autoerotismo femenino? Pienso que los inconvenientes planteados por The Clinic se basan en que "Enamorada de mi clítoris" trata de un placer obtenido con total 
prescindencia del falo. Por mucho que Maliki recurra a la recreación imaginativa de previas relaciones sexuales con hombres para lograr estimularse, el hecho es que la crónica en cuestión la muestra prodigándose placer a sí misma y dialogando con su clítoris, el cual es personalizado, ya que tiene rostro, capacidad de hablar y una insaciabilidad suma (Maliki en tinta china).

El autoerotismo de Maliki así como la representación de su clítoris como un órgano completo y autosuficiente dejan a las claras que, lejos de ser "ese sexo que no es uno" - para usar la terminología de Luce Irigaray -, la mujer no es una carencia o una negatividad por el hecho de no ser hombre. Como la filósofa belga asevera, el psicoanálisis fijó un discurso "verdadero" sobre la sexualidad femenina según el cual:

lo femenino solo tiene lugar en el interior de modelos y de leyes promulgadas por sujetos masculinos. Lo que implica que en realidad no existen dos sexos, sino uno solo. Una sola práctica y representación de lo sexual. Con su historia, sus necesidades, sus reversos, sus carencias, su/sus negativos ... cuyo soporte es el sexo femenino. (65)

"Enamorada de mi clítoris" irrumpe desde el plano privado hacia el público para declarar que lo que define a la mujer no es que ella sea un nohombre debido a su supuesta carencia de un pene. Al contrario, esta historieta celebra la diferencia de la mujer como un ser cuya sexualidad no es falocéntrica y, por lo mismo, no está determinada por la ausencia del órgano sexual masculino. Al sacar a la mujer de la indiferenciación sexual a la que ha sido sometida, niega que su diferencia signifique un no-ser y la libera de la posición de inferioridad a la que había sido relegada.

En su prólogo a The Vagina Monologues, Gloria Steinem recuerda que, independientemente del nivel de educación de las mujeres de su entorno y de lo progresistas que pudieran ser, no usaban un léxico que, con exactitud, hiciera referencia a los genitales femeninos:

I didn't hear words that were accurate, much less prideful. For example, I never once heard the word clitoris. It would be years before I learned that females possessed the only organ in the human body with no function other than to feel pleasure. (If such an organ were unique to the male body, can you imagine how much we would hear about it - and what it would be used to justify?) Thus, whether I was learning to talk, to spell, or to take care of my own body, I was told the name of each of its amazing parts - except in one unmentionable area. This left me unprotected against the shaming words and dirty jokes of the school yard and, later, against the popular 
belief that men, whether as lovers or physicians, knew more about women's bodies than women did. (xxviii-xxix)

En "Enamorada de mi clítoris", Maliki se muestra diestra en el conocimiento de ese órgano cuya única función es el placer sin propósito ulterior, poniendo en evidencia la capacidad de la mujer de ser independiente en la búsqueda y consecución de su propia satisfacción sexual. En Liberating Masturbation, Betty Dodson propone que, para que la mujer alcance su liberación, no basta con que logre ser autosuficiente financieramente hablando. Debe serlo también en el sexo. Para Dodson, la masturbación de la mujer es su auténtica "Declaración de Independencia", ya que conlleva un potencial revolucionario que ha sido acallado por la represión cultural (I). Dodson deconstruye la idea de que la mujer deba sentirse avergonzada y culpable acerca de la masturbación. Desarticula las creencias inculcadas en la mujer sobre esta práctica tales como que menoscabaría su sexualidad o que el placer sexual se obtendría solamente a través de la penetración por parte de un hombre, ya que el deleite proporcionado por el clítoris y auto provocado por la mujer sería señal innegable de inmadurez (Dodson 2). Todas estas presunciones apuntan, asevera Dodson, a ocultarle a la mujer la constatación de un hecho palmario: que el placer sexual puede estar disponible para ella cuando ella quiera.

Siendo ella misma una dibujante, Dodson expuso varios de sus trabajos que presentaban la masturbación desde una óptica positiva. El evento tuvo lugar a fines de la década de los sesenta en la ciudad de Nueva York, y la artista sostiene que pudo apreciar actitudes hostiles en muchos hombres que asistieron a la muestra (Dodson 7 ), puesto que ésta cuestionaba la idea de que la relación sexual con un hombre es necesariamente mejor que el placer obtenido solitariamente. Dodson arguye: "Now when a woman masturbates, she learns to like her own genitals, to enjoy sex and orgasm, and furthermore, to become proficient and independent about it. And our society does not really approve of sexually proficient and independent women" (7). Para Dodson, la reticencia con que sus dibujos fueron recibidos da cuenta del miedo que causa la idea de que la mujer descubra que la penetración por parte de un hombre no es su única fuente de placer y que, por lo mismo, el hombre ya no pueda obtener su tipo favorito de relación sexual (7). Éste es el riesgo de admitir que la mujer pueda satisfacerse a solas. De allí que se le inculque una visión negativa de sus propios genitales que la lleva a privarse de su propio cuerpo y, por ende, a otorgarle valor social solo a través de la maternidad. Así, se mantiene la visión maniquea sobre la mujer, en la que es o la madre virginal y asexuada o la mujer caída, 
esto es, la prostituta. De este modo, la represión sexual juega un papel primordial en mantener a la mujer en los roles de género que le han sido asignados (8).

La búsqueda del placer sexual como tal, con prescindencia de la idea de convertirse en esposa y madre, es otra de las características que Trujillo aborda al enfocarse en la mujer como ente erótico. Maliki es muy activa a la hora de buscar sus compañeros sexuales y tiene muy claras sus preferencias en cuanto al tipo físico masculino que más le atrae. Todo esto cuestiona el "doble estándar", esto es, "the concept that men have social approval to be aggressive (independent) and therefore sexually polygamous but that women should be non-aggressive (dependent) and therefore sexually monogamous" (Dodson 8). En Las crónicas de Maliki 4 Ojos, Trujillo nos hace partícipes de todas las etapas por las que pasan las conquistas de Maliki, desde las conversaciones previas con sus amigas acerca de sus dudas sobre los hombres que le interesan, hasta el acto sexual mismo, descrito con minuciosidad y detalle. Maliki no duda en llevar la iniciativa antes y durante la relación sexual, es asertiva en la manifestación de lo que le gusta y la excita, y es audaz al expresarle a un hombre sus ganas de estar con él, todo lo cual pone de manifiesto que ese hombre es el blanco de su mirada, la cual lo transforma en el objeto de su deseo. La mirada de Maliki revierte la dinámica de la mirada masculina en donde el hombre es quien impone sus fantasías sobre la mujer mientras ésta permanece pasiva y objetivada. Trujillo crea una imagen de la mujer que rivaliza y confronta la representación que comúnmente se encuentra en los cómics, ya que estos suelen usar códigos para representar a la mujer que reproducen y refuerzan el sistema patriarcal.

Al pasar revista a la historia del cómic dedicado a niñas y adolescentes, así como al que presenta personajes femeninos en roles protagónicos y secundarios, Jacqueline Danziger-Russell identifica a Sheena, la Reina de la Selva, como uno de los personajes más interesantes de los comienzos de los libros de cómics, cuyas aventuras fueron publicadas por primera vez en I937. Aunque Sheena se caracterizaba por su fuerza, su habilidad para pelear y su ducho manejo del puñal,

Will Eisner and S.M. Iger's fierce jungle warrior was not created specifically for the enjoyment and empowerment of female readers. Although she was represented as a strong and powerful female, Sheena resembled a pin-up model, designed for the male gaze. Though she would fight and often kill her opponents brutally, yet efficiently, she would do all of this with her statuesque form clad in only the scantiest, often ragged or torn leopard-hide bathing suits. (I2) 
Según Danziger-Russell, la Segunda Guerra Mundial tuvo un impacto en los cómics para niñas y adolescentes en los Estados Unidos. A principios de la década de los cuarenta, las revistas y libros de cómics impulsaban a las niñas a asumir roles más allá de ser esposas, amas de casa y madres. Al encontrarse los hombres fuera del país y combatiendo, las mujeres eran necesarias como fuerza de trabajo y un elemento clave en el esfuerzo común y patriótico impuesto por la guerra. Con todo, solo dos años después de finalizado el conflicto, las revistas de cómics para niñas volvieron a presentar los estereotipos que las habían caracterizado con antelación: adolescentes embobadas con los chicos, que compiten por la atención de los hombres, para lo cual, entre otras cosas, ocultan cuán inteligentes son, pues parece que las mujeres más capaces resultan menos apetecibles para la mirada masculina. Estos cómics normalizan la noción de que para una mujer siempre será preferible una relación insatisfactoria con un hombre antes que estar sola. A estos contenidos debe sumarse una representación gráfica de la mujer como abiertamente insinuante, tomando en consideración que se trataba de revistas para adolescentes (Danziger-Russell 23-25). DanzigerRussell analiza detenidamente algunas portadas de Calling All Girls y concluye que se presenta a la adolescente en una posición de sumisión (de rodillas), exhibiendo sus gruesos labios pintados de rojo, vestida con atuendos ceñidos y asociados a la domesticidad o a una apariencia felina que, como la autora advierte, inserta a la muchacha en unos roles subalternos o altamente sexualizados, lo que es reforzado cuando la joven sostiene en sus manos algún objeto que puede ser considerado un símbolo fálico (25-27). El recuento de Danziger-Russell no termina ahí, pues trae a colación otras publicaciones en las que se reafirman los estereotipos descritos, empujando a las niñas a un regreso al reino de lo doméstico como su lugar natural y, por lo mismo, desincentivando su incursión en ámbitos donde se requiere ser competitiva, como los deportes que tradicionalmente practican los hombres. En general, se representa a las jóvenes obsesionadas por su apariencia y por los muchachos (27-30).

Los movimientos feministas de los años sesenta en los Estados Unidos no tuvieron una influencia real en los cómics. No fue sino hasta el surgimiento del cómic alternativo o underground, llamado "comix", que aparece una serie de periódicos alternativos feministas, entre los que destacó It Ain't Me, Babe, publicado en el área metropolitana de San Francisco (Danziger-Russell 3i). Sin embargo, el mundo del cómic ha sido siempre controlado por hombres, sea en el rol de autores o de consumidores, lo cual ha conducido a que la mujer continúe siendo 
representada como un objeto moldeado por la mirada masculina. DanzigerRussell señala que el camino para que los roles femeninos basados en los estereotipos mencionados hayan cedido espacio a otras visiones sobre la mujer ha sido largo y difícil. Según la autora, "Girl's comics are becoming experimental and literary, offering an alternative to the stereotypes found in mainstream comics, which often continue to objectify the female body and neglect her power as a human being" (Danziger-Russell 392-93). De allí la relevancia de la mencionada revista Brígida - gestionada, entre otras dibujantes, por Marcela Trujillo -, cuyo propósito es construir un espacio exclusivo para autoras de cómics que ofrecen una representación de la mujer a contracorriente de la perspectiva masculina dominante. De hecho, el título de la publicación fue elegido con un objetivo claro: destacar una identidad femenina marcada por su fortaleza, asertividad y capacidad para tomar decisiones, lo que desafía los estereotipos de género.

La maternidad es, sin duda, uno de los roles que ayuda a mantener a la mujer en su lugar, presentándosela como el resultado inevitable y natural de la actividad sexual concebida como actividad reproductiva. Maliki confiesa abiertamente que no deseaba ser madre y que lo llegó a ser para darle en el gusto al amigo que reencuentra en Alemania tras una separación de doce años. Huevo Díaz es quien quiere formar una familia y tener hijos. Maliki solamente busca tener sexo con él. A los veintidós días de su encuentro con Díaz en Hamburgo, y hallándose Maliki en Buenos Aires, descubre que está embarazada. Así termina la crónica "Tu juguito y el mío", con los amantes hablándose por teléfono, prodigándose tiernas frases de amor, consejos sobre los cuidados durante la preñez y expresándose el deseo de estar el uno en los brazos de la otra y viceversa. Sin embargo, en la tercera de las "Crónicas de NYC", titulada "Terror uterino", Maliki expone su miedo a encontrarse con una "guagua no deseada". En la breve carta introductoria dirigida al lector, confiesa: "Me aterra la idea de ser mamá, especialmente de parir". La crónica comienza con una pesadilla ambientada en la orilla de una playa. Allí, Maliki da a luz un bebé, asistida por dos hombres desnudos. La escena resulta ser la toma final de una película y, tan pronto como "la guagua" nace, le dicen a Maliki que debe deshacerse de ella porque ya la filmación ha terminado. Para tal efecto, uno de los hombres le proporciona un cuchillo. Inmediatamente después, Maliki se despierta sobresaltada y llena de dudas ante un posible embarazo, lo cual resulta ser solo una falsa alarma. Finaliza la crónica con otra imagen onírica, pero esta vez vemos a Maliki actuando en una película de ciencia ficción en la que aparece recubierta con un preservativo del que sale una ducha con la que 
baña a un grupo de espermatozoides con lubricante espermicida (Maliki en tinta china).

En El segundo sexo, Simone de Beauvoir expresa vehemente su disconformidad con que a la mujer se la empuje, entre otras cosas, a ser madre, ya que se asume socialmente que, "[e]n virtud de la maternidad es como la mujer cumple íntegramente su destino fisiológico; ésa es su vocación 'natural', puesto que todo su organismo está orientado hacia la perpetuación de la especie" (464). Estas ideas, planteadas hace setenta años, distan mucho de haber desaparecido del horizonte de sentido de un número significativo de sociedades occidentales. Chile, sin duda, se halla entre los países que poseen una visión sobre la mujer como madre profundamente anclada en la idiosincrasia nacional. Maliki, como diría de Beauvoir, se vio obligada a un embarazo "a su pesar" (474). Tres años después, al mirar retrospectivamente esta etapa de su vida, Maliki reconoce que aceptó todas las propuestas de Huevo Díaz por agradecimiento, un sentimiento que brota en el personaje cada vez que un hombre se fija y se interesa en ella, como si le estuviera haciendo un favor que ella debiera reconocer y corresponder. De allí que no importe que el encuentro circunstancial en Hamburgo no sea una base sustantiva para formar una familia. Lo que realmente contaba, como Maliki declara en "Malikimamá" o "Confesiones e infidencias de madre y esposa", es que

Lo que más deseé por largos 34 años ocurrió hace 3: encontré al hombre de mi vida, un viejo amigo, el Huevo Díaz. Estaba tan agradecida que no me importó pololear 5 meses por teléfono y solo r en persona ( $\mathrm{y}$ con guata entremedio). Estuvimos casados y sin hijos por 40 idílicos días y 40 entretenidas noches... Hasta que nació la Lulú, al puro estilo alemán: a lo perrito, a sangre pato, con partera y en cama de dos plazas. (Maliki en tinta china)

Muy pronto, Huevo plantea sus deseos de tener un segundo hijo, idea que Maliki rechaza mientras vivan en Alemania. Para ella, la maternidad ha implicado alteraciones profundas en su estilo de vida. De pronto, se vio esposa y madre sin haberlo planificado. De ser una mujer libre, que disponía de su espacio y tiempo, pasa a estar pendiente de su hija día y noche. Por otra parte, el fervor inicial expresado por el flamante marido comienza a tambalear cuando en Alemania la situación se le vuelve adversa. Es entonces que Maliki sugiere la idea de volver a Chile como condición para considerar la opción de tener otro niño. Es así que Lupita nace al año y dos meses del regreso. En sus representaciones del parto, Trujillo resalta el intenso dolor del momento, contraviniendo el mito de que la madre olvida el sufrimiento 
de dar a luz tan pronto como ve el rostro de su hijo y socavando la imagen materna como pura abnegación y estoicismo. Del mismo modo, dibuja también el dolor que, por lo menos al principio, el amamantamiento le produjo. Mientras Huevo contempla extasiado a Lulú alimentarse del pecho materno, Maliki deja escapar un "Auch!", muy a tono con la expresión de aflicción que evidencia su cara (Diario íntimo 4I). Trujillo recrea más de una vez los eventos que la llevaron a convertirse en madre. En su cómic "Maternidad", Maliki nos dice en una sola palabra lo que el embarazo, el dar a luz, el amamantamiento y el criar a sus hijas ha significado para ella: “'Estar embarazada' es... ¿metamorfósico? 'Parir' es doloroso!! 'Dar teta' es... exclavizante [sic]. 'Criar' es... agotadooor", mientras observamos los diversos dibujos que grafican los estados por los que atraviesa el personaje (Maliki en tinta china). A pesar de que el cómic concluye con “'Tener hijos' es ... ¡lo máximo!”, la autora deja en claro que las imágenes que presentan una visión idealizada sobre la maternidad olvidan que no es natural para la mujer aceptar, como si nada, una transformación tan drástica de su cuerpo, el dolor físico, la pérdida de la libertad y el vivir constantemente cansada. Como Simone de Beauvoir asevera, habría que cuestionar la existencia de un "instinto materno" en la especie humana, ya que "La actitud de la madre es definida por el conjunto de su situación y por el modo en que la asume" (496), así como es un prejuicio sostener que

la maternidad basta... para colmar a una mujer... La relación de la madre con sus hijos se define en el seno de la forma global que es su vida; depende de sus relaciones con su marido, con su pasado, con sus ocupaciones, consigo misma; tan absurdo como nefasto error es pretender ver en el hijo una panacea universal. (507-08)

La imagen de la "mamá monstruo" es ampliamente abordada en $E l$ diario iluminado de Maliki 4 Ojos. Maliki aparece escindida y se dibuja atravesada por una desgarradora contradicción (figura 3). Si en un momento es muy cariñosa con sus hijas, suscitando una respuesta acorde de parte de las niñas, luego pierde el dominio sobre sí, grita y se muestra autoritaria, haciendo que Lulú y Lupita se asusten y lloren. Maliki identifica los monstruos con las frustraciones y complejos originados en la propia infancia, los cuales permanecerían en un estado de adormecimiento y bajo control hasta que la maternidad los libera (Diario iluminado 2I). Opone la "mamá perfecta" a la "mamá monstruo" (23). Al referirse a la primera, nos dice: “...todos nos piden que seamos perfectas... como de catálogo, buenas, impecables, amables, comprensivas, cariñosas, tiernas, eficientes, felices..." (20). Sin embargo, la "mamá perfecta" terminará necesariamente perdiendo 
los estribos, entrando así en un ir y venir entre un estado y otro, lo que la lleva a ser catalogada como "loca" (20-24). No existe un lado de la maternidad sin el otro, postula Maliki; es parte de una dialéctica que, social y culturalmente, es juzgada negativamente - la "mala madre" - cuando se encuentra en su etapa de "monstruosidad". Simone de Beauvoir enfrenta este asunto al desmantelar la noción de "madre desnaturalizada", todavía vigente en Chile. Para de Beauvoir:

No existen madres "desnaturalizadas", puesto que el amor maternal no tiene nada de natural: pero, precisamente por eso, hay malas madres. ... Los complejos, las obsesiones y las neurosis que padecen los adultos tienen sus raíces en su pasado familiar; los padres que tienen sus propios conflictos, sus querellas, sus dramas, representan para el hijo la compañía menos deseable. Profundamente marcados por la vida del hogar paterno, abordan luego a sus propios hijos a través de complejos y frustraciones; y esa cadena de miseria se perpetuará indefinidamente. (509-IO)

Adrienne Rich ve en la noción de madre "natural" una explicación de los sentimientos contradictorios de ternura y enojo que la mujer experimenta hacia sus hijos. Si se entiende a la madre como una persona cuya identidad se define completa y exclusivamente por su ser madre, entonces se da por sentado que su máxima gratificación es estar todo el día con sus niños en su hogar y que su amor debe ser totalmente desinteresado e incondicional. No obstante, Rich apela a su propia experiencia y describe un ciclo que, de alguna manera, se asemeja a la oposición "mamá perfecta" - "mamá monstruo" planteada por Trujillo. Recuerda que cada vez que tomaba un libro o comenzaba a escribir y alguno de sus hijos la interrumpía, ella sentía el enojo crecer dentro de sí porque era como si el niño le impidiera vivir aunque fuera quince minutos para sí misma. Este modelo de maternidad, explica Rich, era entendido como un destino, como la inevitable naturaleza misma de la mujer, aunque implicara su muerte espiritual e intelectual (29). El enojo, entonces, brotaba de la lucha de la madre por su propia vida en contra de sus propios hijos (29), momento al que Rich también se refiere usando el término "monstruosidad". La frustración que lleva a la ira surge de la institución patriarcal de la maternidad presentada como "condición humana", cuando, por el contrario, tiene tras de sí un devenir histórico y una ideología (34).

Trujillo retrata el quiebre interior que se produce en la mujer a causa de una maternidad no buscada, más aún cuando debe hacerse cargo casi por completo de los quehaceres domésticos. El par binario "mamá perfecta" "mamá monstruo" pone un juicio de valor sobre la mujer cuando ésta oscila 
de un polo al otro. Lo dicho se refuerza en las culturas donde la figura de la Virgen María, como modelo máximo de la bondad materna, se halla arraigada, como es el caso de amplios sectores de la sociedad chilena. Trujillo imagina una relación entre Maliki y la imagen de la Dolorosa que se encuentra en la Iglesia de Santa Gemita, en la comuna de Ñuñoa, lugar al que Maliki llega buscando la tranquilidad para meditar en silencio, práctica sugerida por su nutripsicóloga. Es allí donde nuestro personaje entra en conversaciones con la Dolorosa, momento en que ambas comparten sus cuitas. Maliki es confortada por la Virgen María, quien le dice que todos sufren, "Sobre todo las mujeres..." (Diario íntimo 74). Maliki asiste durante dos semanas a lo que llama sus "consultas" con la Dolorosa, de quien se siente una "paciente" (75). Esta relación con la Virgen María está traspasada de tonos psicoanalíticos y feministas, pues Maliki descarta completamente a Dios, a quien identifica como hombre y, por lo mismo, como portador de ese discurso universalizante que anula lo femenino en su especificidad:

Cuando era chica las monjas me enseñaron a rezarle directamente a Dios, pero yo sentía que ponerme en manos de una mujer era más lógico. Dios no podría entender todo lo que me estaba pasando, pero la Virgen sí y más encima la Dolorosa, que lo único que hacía era estar arriba de ese altar sufriendo por su hijo. Además la nutripsicóloga me había explicado todo este asunto de solucionar los conflictos con la madre para tener una vida sentimental amorosa sana, por lo tanto Dios no venía al caso. (Diario íntimo 75)

Al terminar sus "consultas" con su "terapeuta espiritual", Maliki se lleva a casa una estatuilla de la Virgen de Guadalupe que compra en la tienda de la iglesia. El vínculo entre Maliki y la Virgen se halla permeado por un humor que también sugiere matices feministas. Cuando la Virgen no despierta temprano a Maliki para que ésta prepare a sus hijas para llevarlas al colegio, se excusa diciendo: "Lo siento, yo también me quedé dormida" (79), lo cual debilita la imagen de madre perfecta con la que se asocia la figura de la Virgen María. Lo interesante es que quedarse dormida desencadena la pérdida de control que lleva a Maliki a alzar la voz y a mostrar gestos de impaciencia que terminan por hacer llorar a las niñas. Al admitir que se quedó dormida, la Virgen de Guadalupe reconoce que es igualmente capaz de entrar en esa vorágine que lleva a que la madre monstruo se haga presente. De este modo, se socava el modelo de perfección inculcado en las mujeres desde la niñez y, en su lugar, aparece una mujer cercana a la que Maliki siente como su igual. 
Indudablemente, Marcela Trujillo crea a Maliki 4 Ojos como su alter ego. El personaje toma sobre sí diversos roles, siempre con humor, para así poder hablar sobre temas que, de suyo, no tienen nada de divertido. Los diversos derroteros por los que el lector sigue a Maliki dan cuenta de que, muchas veces, el personaje asume los estereotipos de género tan extendidos en la sociedad chilena. La mujer que sueña con un príncipe azul o que anhela fervorosamente ser atractiva para la mirada masculina o que imagina que será una madre perfecta son algunos de los lugares comunes que Maliki inicialmente abraza y vive intensamente para, muy pronto, darse cuenta de la gran decepción que supone la adhesión a tales ideales. La adopción de unos paradigmas que le fueron imbuidos desde la infancia conlleva un profundo menoscabo de su ser. Las heridas causadas por el desengaño de los modelos en que tanto creyó y a cuya consecución se consagró son visibles a pesar de la caricatura con que retrata esas frustraciones.

La preferencia de Trujillo por el diario íntimo revela su afán de llegar a ser la creadora de su identidad como mujer y de producir su autorretrato. La proximidad entre autora y personaje le permite re-visitar su pasado y visualizar cuán vehementemente deseó llenar unas expectativas impuestas desde unos modelos de femineidad producidos por la mirada masculina imperante. Con todo, al ficcionalizar su historia personal a través de Maliki, Trujillo sugiere que la realidad extra-textual y la propia vida también pueden ser imaginadas. Desde sus diarios, Trujillo hace visible un universo íntimo que busca su propio modo de expresión y que se niega a ser dicho y retratado a través de modelos masculinos de subjetividad. Es ese mundo personal el que se vuelca en los dibujos de la autora, creando así un puente entre el género autobiográfico y el cómic.

Como se ha dicho, ni siquiera en los segmentos donde predomina la escritura Trujillo deja de dibujar, pues, al trazar las letras, las vivifica, les insufla un movimiento que manifiesta y desvela un mundo ilimitado de emociones y sentimientos. La comicidad le ayuda a la autora no solo a retratar sus propias paradojas interiores sin juzgarse lapidariamente, sino que puede también motivar a que otras mujeres reconozcan y, más importante aún, se reconozcan en ciertas actitudes y, a partir de ahí, se sientan incentivadas a ejercitar su capacidad autocrítica. Como lo habitual tiende a pasar inadvertido debido precisamente a su cercanía y cotidianidad, el que los cómics de Trujillo caricaturicen ciertas situaciones y las presenten con sentido del humor predispone a las lectoras favorablemente hacia la autorreflexión. Trujillo evita condenar a las mujeres que se han adaptado a los estereotipos de género porque semejante actitud bien podría producir una cerrazón, haciéndolas rechazar lo que 
percibirían como un ataque. Los cómics de Marcela Trujillo se ofrecen, así, como una auténtica exhortación tendida al público - especialmente el femenino - para que se deje interpelar por estas historietas que, de modo provocador, instan a no cejar en el proceso nunca acabado de la construcción de la propia identidad.

Washington State University

\section{OBRAS CITADAS}

Cano Calderón, amelia. "El diario en la Literatura. Estudio de su tipología."

Anales de Filología Hispánica 3 (1987): 53-60.

D AN ZI G E R-R USS E L, JA QU E L ine. Girl and Their Comics. Finding a Female Voice in

Comic Book Narrative. Lanham: The Scarecrow P, 2013.

De beauvoir, simone. El segundo sexo. Trad. Juan García Puente. Buenos Aires:

Editorial Sudamericana, I999.

D O D S ON, B E T T Y. Liberating Masturbation. Unpublished manuscript. S. pág. Web.

el refaie, elisa beth. Autobiographical Comics. Life Writing in Pictures. Jackson:

UP of Mississippi, 2012.

H IERRO, MANUEL. "La comunicación callada de la literatura: reflexión teórica sobre

el diario íntimo." Mediatika (1999): 103-27.

H I T E, M O L L Y. The Other Side of the Story: Structures and Strategies of Contemporary

Feminist Narrative. Ithaca: Cornell UP, 1989.

I I I G RAY, L UCE. Ese sexo que no es uno. Trad. Raúl Sánchez Cedillo. Madrid: Akal,

S.A., 2017.

LUQUE AMO, ÁlVARO. "El diario personal en la literatura: Teoría del diario

literario." Castilla. Estudios de Literatura 7 (2016): 273-306.

M I C H A LS KI, A N D RÉ. "El retrato retórico en la obra cervantina." Cervantes: Su obra y su mundo. Actas del I Congreso Internacional sobre Cervantes. Ed. Manuel Criado de Val. Madrid: Patronato Arcipreste de Hita, 1981. 3946.

mulvey, LAura. "Visual Pleasure and Narrative Cinema." Media and Cultural

Studies. Keyworks. Eds. Meenakshi Gigi Durham y Douglas M. Kellner. Malden:

Blackwell Publishing, 2006, 342-52.

PICARD, HANS RUDOLF. "El diario como género entre lo íntimo y lo público."

Anuario de la Sociedad Española de Literatura General y Comparada 4 (I98I):

II5-22.

RICH, A D R IE N N E. Of Woman Born. Motherhood as Experience and Institution. New

York: W.W. Norton, 1976.

RiVAS, matías. “Osadas y crudas.” Culto, 9 de septiembre 20I7: S. pág. Web. 
S TE Ine M, GL o RiA. Foreword. The Vagina Monologues. Por Eve Ensler. New York: Villard Books/The Random House Publishing Group, 2008. xxvii-xxxviii. TRAPIEllo, AN DRÉs. El escritor de diarios. Madrid: Península, 1998.

T R u I l lo, mar C e la. El diario iluminado de Maliki 4 Ojos. Santiago: Ocho Libros Editores, 2013.

—. El diario íntimo de Maliki 4 Ojos. Santiago: RIL Editores, $20 \mathrm{II}$.

-. Maliki en tinta china. Obras incompletas. Santiago: Ocho Libros Editores, 2013 .

Waugh, Pa t Ricia. Metafiction. The Theory and Practice of Self-Conscious Fiction. London: Routledge, I990. 


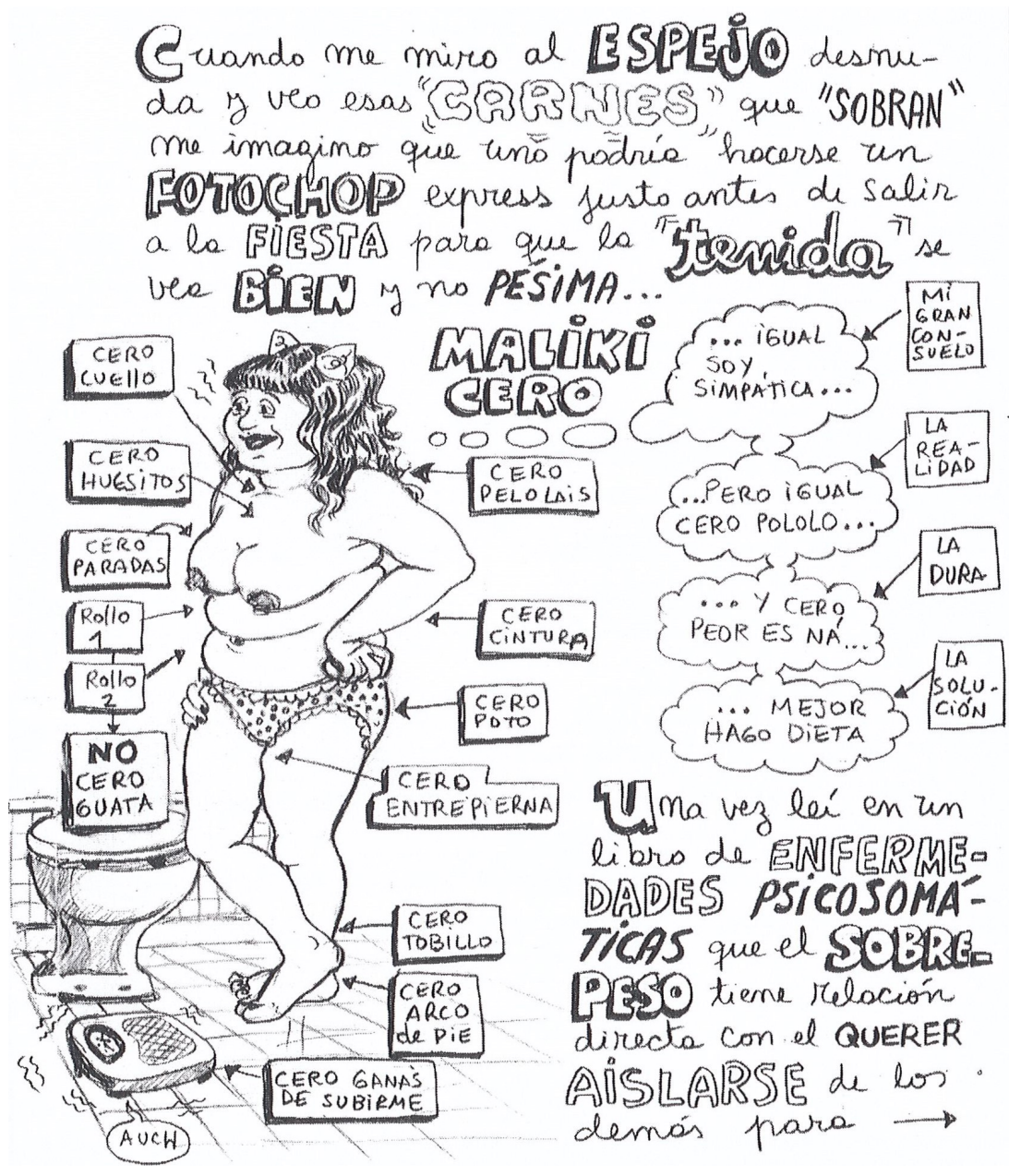

Figura I- "Maliki cero" 

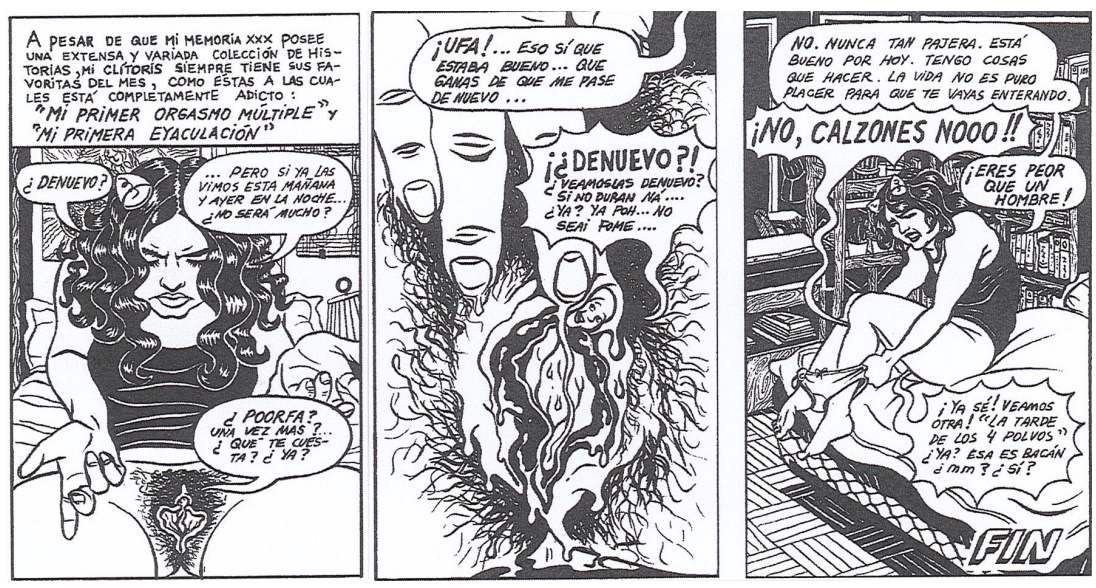

Figura 2 - "Enamorada de mi clítoris" (fragmento) 


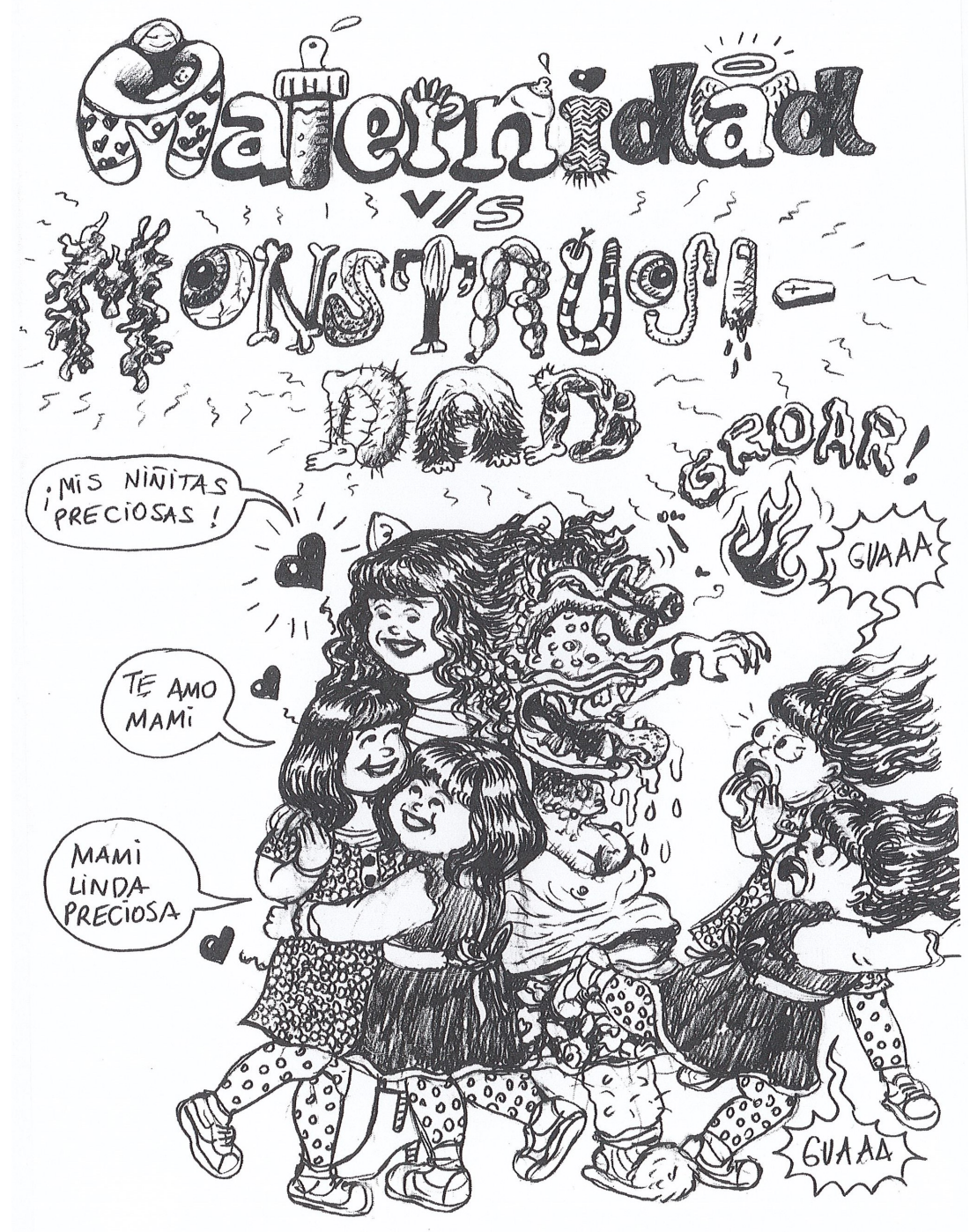

Figura 3 - "Maternidad v/s Monstruosidad 